\title{
An Empirical Study on relationship among Quality of work life and its factors
}

\author{
Preethi vijaimadhavan ${ }^{1,}$ Dr. D. Venkatarama Raju M.Com., M.Phil., Ph.D. ${ }^{2}$ \\ ${ }^{1}$ (Vels University, Chennai, Tamil Nadu,India) \\ ${ }^{2}$ (Department of Commerce, Pachaiyappa's College, Chennai, Tamil Nadu, India)
}

\begin{abstract}
Q W L$ is a very important concept of favorable situation in a working environment. $Q W L$ helps the management and employees by facilitating training opportunities, job satisfaction and working condition. A satisfied employee is one who has a career growth along with the organization growth. Sample of 826 respondents were collected from IT industry. The factor analysis was applied to find out the underlying variance among the variables. the results of exploratory factor analysis confirmed that the measurement scales used in this study satisfactorily met the standards of validity and reliability analyses. This study used empirical research methods to explore the correlation between QWL factors. That provided a new way of thinking and measures how to improve the QWL of IT professionals and the organization Performance. Conclusion of this study is elaborated.
\end{abstract}

Keywords: Quality of Working Life; Job Satisfaction; Working condition; General well-being; Work life balance

\section{Introduction}

Increase in MNCs and changes in lifestyle have made an impact and led to the importance in the quality work life for an employee. Quality of work life is the level of happiness or dissatisfaction with one's career. Employers have started concentrating on providing best work environment to its employees to get the best results. A good quality of work life reduces absenteeism, accidents \& attrition. Quality of work life is useful to improve production, organizational effectiveness, morale of an employees and economic development of the country.

QWL had been defined as "The quality of relationship between the employees and the total working environment". Quality of Work Life is the essential concept of favorable situations in a working environment. A better Quality of Work Life improves the growth of the employee's along with the organization growth (Pugalendhi, Subburethina, Umaselvi, Nakkeeran, Senthil 2011). GunaSeelan \& Maimunah 2008 defines QWL as the effectiveness of work environment that transmit to the meaningful organizational and personal needs in shaping the values of the employees that support and promote better health and well-being, job security, job satisfaction, competency development and balance between work and non-work life. This definition quantifies the QWL among the IT professionals with the aim to gain leverage in recruiting, motivating and retaining the valuable IT workforce as the nature of work continues to diversify. Quality of work life has been defined as a philosophy or a set of principles, which holds that people are trustworthy, responsible and capable of making a valuable contribution to their organization. It also involves treating people with respect (Farideh, 2012)

\subsection{Constructs of Quality of work life}

In recent times many studies have been done on Quality of Work Life of employees. The study by Raduan, Loh, Jegak and Khairuddin 2006 revealed three exogenous variables are significant career-related dimensions that are (1) career satisfaction, (2) career achievement, and (3) career balance. In a new perspective the authors proposed career related factors as the most important predictors of Quality of work life. Argentero, Miglioretti \& Angilletta2007 has proposed five quality of work life indicators: (1) Professional Relationship, (2) Work Organization, (3) Taking Care (4) Professional Ability and Professional Growth. According to them the professional relationship has been the first indicator of Quality of work life. Lokanadha M , Mohan 2010 have suggested five emerging dimensions of QWL which include health and wellbeing, job security, job satisfaction, competence development and the balance between work and non-work life. Walton's eight major conceptual categories relating to QWL was a widely used constructs for the study of QWL they are (1) adequate and fair compensation, (2) safe and healthy working conditions, (3) immediate opportunity to use and develop human capacities, (4) opportunity for continued growth and security, (5) social integration in the work organization, (6) constitutionalism in the work organization, (7) work and total life space and (8) social relevance of work life. (Ayesha 2012; Alireza, Rezaeean, Jafar, Sona, and Amir 2011; Meenakshi, Parul 2011, Subaashnii, Fitriya, Thilageswary; Sofi, Razzaghi, Hajelo 2012). Reviews of the Quality of work life 
indicators in organizational literatures identified criteria consistent with issues expressed in Information technology and software literatures. (Chandranshu 2012).

A recent statistical analysis of a new measure, the Work-Related Quality of Life scale (WRQoL) by QoWL organization, provides support for the psychometric structure of this instrument. The Work-Related Quality of Life scale (WRQoWL) measure uses six core factors to explain most of the variation in an individual's quality of working life: (1)Job and Career Satisfaction, (2) Working Conditions, (3) General WellBeing, (4) Home-Work Interface, (5)Stress at Work and, (6) Control at Work. (Simon, Darren 2012) Emin, Serpil, Neslihan, Darren, 2013, measured the WRQoL scale and the authors concluded that the WRQoL scale was valid and reliable. In a new perspective (M. Swapna \& S. Gomathi, 2013) propose six dimensions measuring Quality of Work Life which included job related factors and also employees growth related factors like career prospects and training \& development. Thus the dimensions used to measure QWL in this study are:

1. Job and career satisfaction

2. Working condition

3. General Well-being

4. Home work interface / Work life balance

5. Career prospects and compensation

6. Training and Development

\section{Objective of the Study}

The objective of the study is to find the factors that influence the Quality of work life of IT professionals and also to measure the relationship between Quality of work life and its factors.

\section{Research Method}

This study is based on primary data and secondary data. Primary data was collected from 826 IT professionals. Questionnaire was designed to collect data on issues related to Quality of Work life. Variables in the questionnaire were selected based on the previous studies. The questionnaire was randomly distributed to software professionals working in IT organization. A total of 826 employees in IT sector responded to the survey. A quantitative research design was employed beginning with the literature review to guide the design of the interview questionnaires. The study focused on IT professional's Quality of work life.Items was measured using Linkert's scale. Empirical research work has been carried out to understand the relationship among the construct of QWL of IT employees.

\section{Analysis \& Result}

The factors of QWL are composed of several variables in likerts 5 point scale. It ranges from strongly agree to strongly disagree. The variables are reduced in to predominant factors which would pave the way to analyze the QWL of IT in a microscopic manner. The reduction system is systematically done through factor analysis by principle component method. Principle component method is applied on the variables and derived the sub factors of Job and Career Satisfaction, working condition, General wellbeing, Home-work interface, Career prospects \& Compensation, Training \& Development.

\subsection{Exploratory Factor Analysis}

Exploratory factor analysis (EFA) is a technique to help an investigator to understand the relationships among variables, represent the validity of constructs, extract common factors, and reproduce or explain the correlation matrix by examining the correlation of large sets of items among interval-level variables. (Leech et al., 2005; Sheng, Ralph, Jung 2009) To establish construct validity in this study, EFA was conducted to further validate the instrument and examine the underlying structure for the total items of each variable.

The application of factor analysis on the variables derived the following research.

Table 1 KMO and Bartlett's Test

\begin{tabular}{|l|l|l|l|}
\hline & $\begin{array}{l}\text { Kaiser-Meyer- } \\
\text { Olkin }\end{array}$ & $\begin{array}{l}\text { Bartlett's } \\
\text { Test }\end{array}$ & P \\
\hline Job \& Career Satisfaction & .843 & 3733.492 & .000 \\
\hline Working Condition & .807 & 3535.89 & .000 \\
\hline General well-being & .870 & 3379.47 & .000 \\
\hline Work life balance & .827 & 1511.3 & .000 \\
\hline Career Prospects \& Compensation & .904 & 2059.57 & .000 \\
\hline Training \& Development & .877 & 1782.79 & .000 \\
\hline
\end{tabular}

TABLE 1 shows KMO measure of sampling adequacy, Bartlett's test of SPhericity with approx chi square value of all are statistically significant at $5 \%$ level, this shows that the sample size of research is 
adequate and they form a normal distribution. These leads to the verification of range of variances for all the variables in each constructs

The Job satisfaction variable exhibits the variances ranging from 0.485 to 0.698 . This shows that the respondent perceived the variation in their opinion which lies between $48.5 \%$ to $69.8 \%$. Similarly working condition variables exhibits the variances ranging from 0.151 to 0.714 . the respondent perceived the variation their opinion in between $15.1 \%$ to $71.4 \%$. The General well-being respondents perceived variance from 0.324 to 0.714 . Variation lies in between $32.4 \%$ to $71.4 \%$. The work life balance the variances ranging from 0.313 to 0.700 and the respondent opinion lies in between $31.3 \%$ to $70.0 \%$. Career prospects and compensation variances ranging from 0.564 to 0.971 . the respondent perceived the variation their opinion which lies in between $56.4 \%$ to $97.1 \%$. Training \& Development variable exhibit the variances ranging from 0.559 to 0.917 and the variation in between $55.9 \%$ to $91.7 \%$. Therefore it can be concluded that the variance is sufficient enough to segment the variables in to predominant factors. The variables are reduced in to predominant factors.

Table 2 Total Variance Explained

\begin{tabular}{|c|c|c|c|}
\hline & $\begin{array}{r}\text { Factors } \\
\end{array}$ & $\%$ of variance & Cumulative \% \\
\hline \multirow[t]{4}{*}{ Job Satisfaction } & Employee relationship & 21.896 & 21.896 \\
\hline & Work nature & 16.936 & 38.832 \\
\hline & Job autonomy & 11.438 & 50.271 \\
\hline & Job security & 7.594 & 57.864 \\
\hline \multirow{3}{*}{$\begin{array}{l}\text { Working } \\
\text { Condition }\end{array}$} & Work Environment & 15.959 & 15.959 \\
\hline & Social Environment & 14.964 & 30.923 \\
\hline & $\begin{array}{l}\text { Psychological } \\
\text { Environment }\end{array}$ & 11.957 & 42.879 \\
\hline \multirow{3}{*}{$\begin{array}{l}\text { General Well- } \\
\text { Being }\end{array}$} & Physical health & 23.587 & 23.587 \\
\hline & Depressive symptom & 15.800 & 39.386 \\
\hline & Work Stress & 12.026 & 51.412 \\
\hline \multirow[t]{2}{*}{ Work life balance } & Work to family interference & 34.014 & 34.014 \\
\hline & Family to work interference & 16.664 & 50.679 \\
\hline \multirow{4}{*}{$\begin{array}{l}\text { Career prospectus } \\
\& \text { Compensation }\end{array}$} & Motivation & & \\
\hline & Career Satisfaction & 20.239 & 42.919 \\
\hline & Interpersonal communication & 17.566 & 60.484 \\
\hline & Efforts by employer & 13.906 & 74.390 \\
\hline \multirow{2}{*}{$\begin{array}{l}\text { Training \& } \\
\text { Development }\end{array}$} & Specified to job purpose & 43.862 & 43.862 \\
\hline & Self-Efficacy & 24.427 & 68.289 \\
\hline
\end{tabular}

TABLE 2 Shows the factors extracted from the factor analysis. Job satisfaction has extracted 4 factors which mainly show the satisfaction an employee receive from the job related factors. The four factors are thus named as Employee relationship, Work nature, Job autonomy, Job Security. Working condition has extracted 3 factors which shows the environment in which the employees work. The environment includes social as well as psychological environment. As it forms a great impact on the employees work. Thus it is names accordingly as work, social and psychological environment. The third variable General well-being shows about the health and mental issues an employee goes through because of work pressure. So it is named Physical health, Depressive symptom, Work stress. The fourth variance Work life balance extracted 2 factors that is work interfering family and family interfering work and it is named as Work to family interference and family to work interference. The fifth variance Career prospectus and compensation extracted 4 factors which shows the career growth, promotion opportunities and pay of an employee which is a vital part of good work life thus it is named as Motivation, Career satisfaction, Interpersonal communication and Efforts by employer respectively. The sixth variance Training \& Development have extracted 2 factors which shows that training provided by the employer and self development efforts and evaluations by employee are important for a career growth thus it is named specified to job purpose and self-efficacy.

The application of factor analysis derived the predominant sub factors for the QWL. The factors identified are predominant in influence Quality of work life of IT professionals. The intercorrelations among these factors are shown in the following table. The correlation matrix decides the nature of relationship. 
Table 3

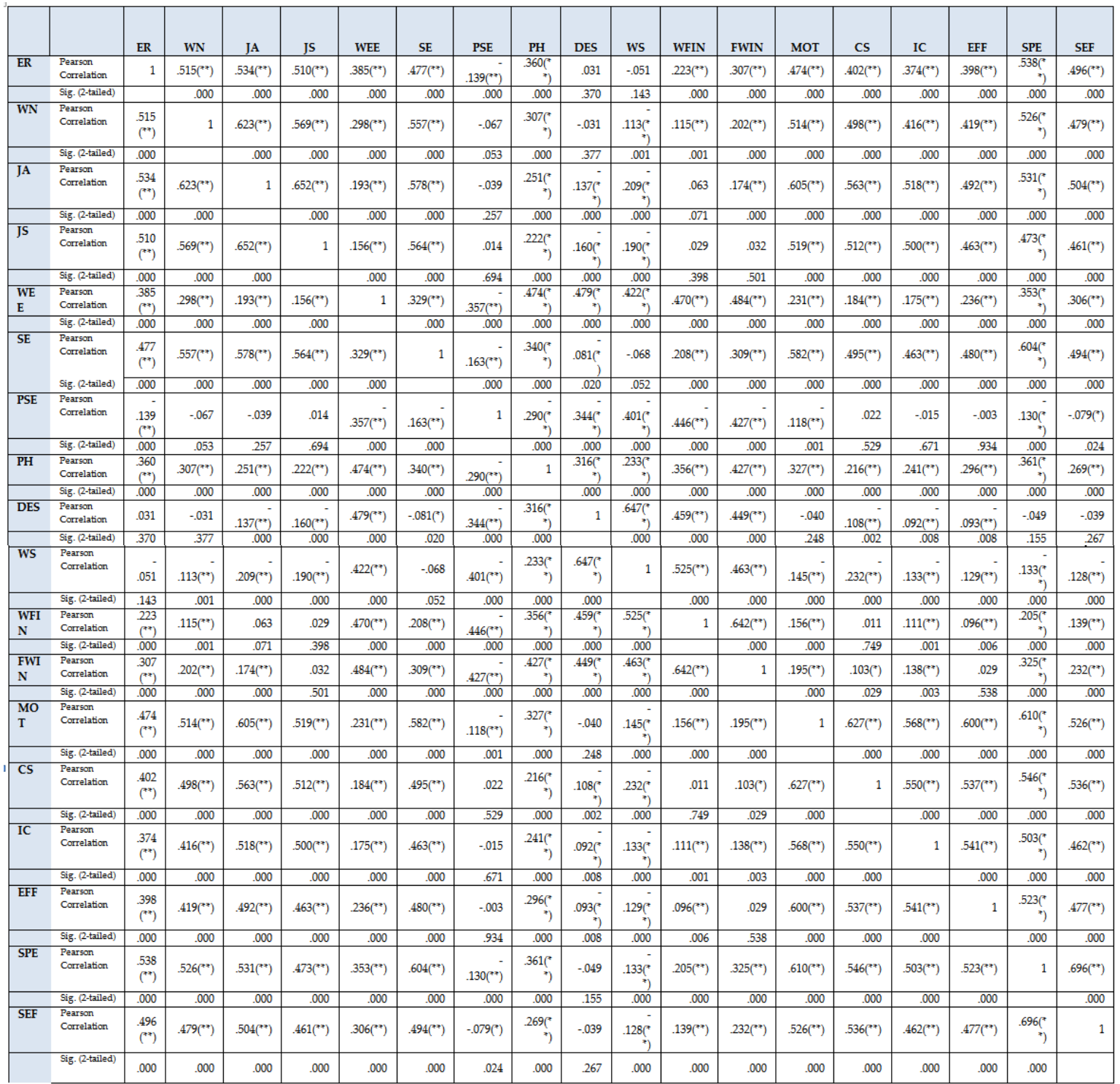

ER - Employee relationship, WN - Work nature, JA - Job autonomy, JS- Job Security, WE - Work environment, SE- Social environment, PSE- Psychological environment, PH - Physical health, DES Depressive symptom, WS - work stress, WFI- work family interference, FWI - family work interference, MOTmotivation, CS- Career satisfaction, IC-Interpersonal communication, EFF- Efforts by employer, SPE- Specified to job purpose, SEF-Self-Efficacy

TABLE 3 shows the correlation between the 18 factors that were identified to be influencing the Quality of work life of employees. The intercorrelation between the factors are elobarately discussed with literature support.

\subsubsection{Employee Relationship}

Employee Relationship is positively correlated to specific job purpose $(.538, \mathrm{p}=.000)$ Job autonomy $(.534, \mathrm{p}=.000)$, Work nature $(.515, \mathrm{p}=.000)$, job security $(.510, \mathrm{p}=.000)$, self efficacy $(.496, \mathrm{p}=.000)$, social environment $(.477, \mathrm{p}=.000)$, motivation $(.474, \mathrm{p}=.000)$, career satisfaction $(.402, \mathrm{p}=.000)$, while the other aspects Efforts by employer $(.398, \mathrm{p}=.000)$, Interpersonal communication $(.374, \mathrm{p}=.000)$, Physical health $(.360$, $=.000)$, family to work interference $(.307, \mathrm{p}=.000)$, work to family interference $(.233, \mathrm{p}=.000)$ have positive but low correlation at 5\% level. Literature shows a positive relationship between Employee relationship and the need to perform jobs that are challenging and that provide variety, interest and stimulation (wanda, Rene) The correlation between employee relationship and job autonomy, work nature, job security is supported by Ronel Erwee 1990 Positive interpersonal relations can facilitate supervisors to convey his objectives, assign jobs or tasks and motivate employees smoothly. Close interpersonal relations with managers also make subordinates 
productive and be willing to give feedbacks. Interpersonal relationships serve as the main basis for developing and maintaining smooth group work or business operations the lack of interpersonal harmony will interrupt the teamwork that needs much cooperation to fulfill objectives. (Xiaoyan \& Lan 2013) Employee relationship is positively correlated with almost all the factors.

\subsubsection{Work Nature}

Work nature is positively and highly correlated to Job Autonomy(.623, $\mathrm{p}=.000)$ Job security $(.569$, $\mathrm{p}=.000)$ Social environment $(.557, \mathrm{p}=.000)$ specific job purpose $(.526, \mathrm{p}=.000)$ Motivation $(.514, \mathrm{p}=.000)$ Career Satisfaction $(.498, p=.000)$ Self efficacy $(.479, p=.000)$ Efforts by employer $(.419, p=.000)$ Interpersonal communication $(.416, \mathrm{p}=.000)$ other factors such as Physical health $(.307, \mathrm{p}=.000)$ work environment $(.298, \mathrm{p}=.000)$ family to work interference $(.202, \mathrm{p}=.000)$ work to family interference $(.115$, $\mathrm{p}=.000)$ at $5 \%$ level positive and very low correlation. work nature is negatively correlated with work stress ($.113, \mathrm{p}=.000) @$ at $5 \%$ level. This indicates that the Work nature of women professionals have significant influence on Job autonomy previous research shows professional women have moderate correlation between service that is the work and Job autonomy (Ronel 1990). The study by Peter 2006 on career anchor reveals the relationship between job autonomy, job security, specific job purpose, self efficacy.

\subsubsection{Job Autonomy}

Job autonomy positively and highly correlated to Job security (.652, $\mathrm{p}=.000)$ Motivation $(.605$, $\mathrm{p}=.000)$ Social environment $(.578, \mathrm{p}=.000)$ Career satisfaction $(.563, \mathrm{p}=.000)$ specific to job purpose $(.531$, $\mathrm{p}=.000)$ Interpersonal communication $(.518, \mathrm{p}=.000)$ Self efficacy $(.504, \mathrm{p}=.000)$ Efforts by employer(.492, $\mathrm{p}=.000)$ whereas Physical health $(.251, \mathrm{p}=.000)$ work environment $(.193, \mathrm{p}=.000)$ family to work interference $(.174, \mathrm{p}=.000)$ at $5 \%$ level have positive but very low correlation. Job? autonomy is negatively correlated with Depressive symptom $(-.137, \mathrm{p}=.000)$ Work stress $(-.209, \mathrm{p}=.000)$ This shows that job security that is the job tenure and fear of losing the job does have a greater impact on job autonomy of IT professionals. This finding is supported by previous researches on career anchors which found the relationship between the job security and the job autonomy (Ronel 1990) Of the various factors that contribute to organizational success, job autonomy and control are important for sustaining and improving employee contribution to the organization. job autonomy is one of the required factors for creating a supportive work environment ( Mary, Vikram, Nancy \& Borich 2012)

\subsubsection{Job Security}

Job Security positively correlated to social environment $(.564, \mathrm{p}=.000)$, Motivation $(.519, \mathrm{p}=.000)$ Career satisfaction $(.512, \mathrm{p}=.000)$, Interpersonal communication $(.500, \mathrm{p}=.000)$ Specific job purpose $(.473$, $\mathrm{p}=.000)$ Efforts by employer (.463, $\mathrm{p}=.000)$ Self efficacy( $.461, \mathrm{p}=.000)$ Physical health $(.222, \mathrm{p}=.000)$ Work environment (.156, $\mathrm{p}=.000)$ at $5 \%$ level. The job security and the social environment are moderate and positively correlated. This indicates that the job security that is the tenure of women professional work life depends on the social environment that is the action against harassment, giving up leisure time or activities for work. This study was supported by previous research found that the social environment and job security were consistent ( Rasool Davoudi, Seyed Hossein Mousavi 2012). Employers can no longer promise job security, but they can help people maintain the skills they need to remain viable in the job market Chandranshu 2012 There is a negative correlation between Job security and Work stress $(-.190, \mathrm{p}=.000)$ Depressive symptom $(-.160, \mathrm{p}=.000)$, at $5 \%$ level

\subsubsection{Work Environment}

Work environment positively and moderately correlated to family \& work interference $(.484, \mathrm{p}=.000)$ Depressive symptom $(.479, \mathrm{p}=.000)$ physical health $(.474, \mathrm{p}=.000)$ Work \& family interference $(.470, \mathrm{p}=.000)$ Work stress $(.422, \mathrm{p}=.000)$ Specific job purpose $(.353, \mathrm{p}=.000)$ Social environment $(.329, \mathrm{p}=.000)$ Self efficacy $(.306, p=.000)$ Efforts by employer $(.236, p=.000)$ Motivation $(.231, p=.000)$ Career satisfaction $(.184, p=.000)$ Interpersonal communication $(.175, \mathrm{p}=.000)$ at $5 \%$ level. There is a negative correlation between Work environment and Psychological environment $(-.357, \mathrm{p}=.000)$ at $5 \%$ level. Similarly there is a negative correlation between social environment and Depressive symptom $(-.081, \mathrm{p}=.000)$ at $1 \%$ level. It is found that work environment negatively correlated with psychological environment $(-.139, \mathrm{p}=.000)$ Previous studies show that the work environment influenced by the job performance(Alla, Helena, Simona, May 2008). The research by Aloys Nyagechi 2013 on work environment factor that affect QWL revealed that poor safety and health, work pressure or stress and provision of inadequate working tools are environmental aspects that bring about poor quality of working life experiences. 


\subsubsection{Social Environment}

There is a positive correlation between Social environment and Specific to job purpose (.604, $p=.000)$ Motivation $(.582, \mathrm{p}=.000)$ Career satisfaction $(.495, \mathrm{p}=-.000)$, Self Efficacy $(.494, \mathrm{p}=.000)$ Efforts by employer $(.480, \mathrm{p}=.000)$ Interpersonal communication $(.463, \mathrm{p}=.000)$ Physical health $(.340, \mathrm{p}=.000)$, Family \& work interference $(.309, \mathrm{p}=.000)$, work \& family interference $(.208, \mathrm{p}=.000)$ at $5 \%$ level. There is a negative correlation between social environment and Psychological environment $(-.163, p=.000)$ at 5\%level Work-related identities, derived from different social environment through identity formation processes, have as behavioral guides a significant influence on employee behavior, which, in turn has an impact on work outcomes This implies that the work-based identity of the collective labour force has an indirect but nevertheless significant impact on organizational performance. Kamarul (2010) concluded that higher superior-subordinate congruence would lead to higher satisfaction and performance of the subordinate which supported the positive correlation between social environment and specific job purpose

\subsubsection{Psychological Environment}

Psychological Environment is negatively correlated to Work \& family interference (-.446) Family \& work interference (-.427) work stress (-.401) Depressive symptom (-.344) physical health (-.290) Specific to job purpose (-.130) motivation (-.118) at 5\% level Self Efficacy (-.079) at 1\% level. Healthy jobs and workplaces contribute to an individual's physical, psychological and social well-being. These benefits ripple across the entire organization through higher job satisfaction, lower absenteeism and turnover, improved job performance, and reduced health benefit (Graham S 2004) according to (R. B. Briner 2000) The psychological environment is the set of those characteristics of work environment that affect how the worker feels, thinks and behaves.

\subsubsection{Physical health}

Physical health positively and moderately correlated with Family \& work interference (.427, $\mathrm{p}=.000)$ specific job purpose $(.361, \mathrm{p}=.000)$ work \& family interference $(.356, \mathrm{p}=.000))$ Motivation $(.327, \mathrm{p}=.000)$ Depressive symptom $(.316, \mathrm{p}=.000)$ Efforts by employer $(.296, \mathrm{p}=.000)$ self efficacy $(.269, \mathrm{p}=.000)$ Interpersonal communication $(.241, \mathrm{p}=.000)$ work stress $(.233, \mathrm{p}=.000)$ Career satisfaction $(.216, \mathrm{p}=.000)$ at $5 \%$ level. In research by Gandi, Wukatda, Yohanna (2011) The role of work-home interference (WHI) and homework interference (HWI) with respect to work characteristics, burnout, and gender were analyzed and was found that home work interference were found to mediate the relationship between work characteristics and burnout which in turn affects they physical health of the employee. High home roles and workloads seems contributory to high level of exhaustion. The findings is also supported by Nicholas (2013) that the physical health inversely correlated with Family and work interference. The study by M. Swapna \& S. Gomathi, 2013)The study elicits that female respondents are not satisfied compared to male employees towards career prospects, compensation and training and development because of their family commitment and health related issues

\subsubsection{Depressive symptom}

Depressive symptom positively correlated to Work stress $(.647, \mathrm{p}=.000)$ work \&family interference $(.459, \mathrm{p}=.000)$ family $\&$ work interference $(.449, \mathrm{p}=.000)$ at $5 \%$ level. There is a negative correlation between Depressive symptom and career satisfaction $(-.108, \mathrm{p}=.000)$ Efforts by employer $(-.093, \mathrm{p}=.000)$ Interpersonal communication $(-.092, \mathrm{p}=000)$. There is a negative correlation between Depressive symptom and career satisfaction $(-.108, \mathrm{p}=.000)$ Efforts by employer $(-.093, \mathrm{p}=.000)$ Interpersonal communication $(-.092, \mathrm{p}=000)$ at $5 \%$ level. There is a positive but very low correlation between Depressive symptom level career satisfaction $(.103, \mathrm{p}=.000)$ at $1 \%$ level. From an individual perspective, stress is related to a wide variety of health related problems, including anxiety, headaches, depression, influenza, coronary disease, and substance abuse.

(GIDEON 2006) In the study conducted by Nicholas (2013) respondents indicated how frequently they experienced minor health problems, sleep problems affecting job performance, feeling nervous or stressed, unable to control important things in life, feeling unable to overcome difficulties, and depression.

\subsubsection{Work Stress}

The findings on work stress are consistent with numerous previous studies. Work stressors have been shown to be inversely associated with work /family interference. Work stressor would be expected to heighten conflict with work/family interference. (Nicholas 2013) Work stress is positively correlated to Work \& family interference $(.525, \mathrm{p}=.000)$ family \& work interference $(.463, \mathrm{p}=.000)$ at $5 \%$ level.

\subsubsection{Work family interference}

Work family interference is positively correlated to Family work interference $(.642, \mathrm{p}=.000)$ specific job purpose $(.205, \mathrm{p}=.000)$, motivation $(.156, \mathrm{p}=.0000)$ self efficacy $(.139, \mathrm{p}=.000)$ Interpersonal communication 
$(.111, p=.000)$ efforts by employer $(.96, p=.000)$ at $5 \%$ level. This shows that the work/family interference and family/work interference are highly influential for women professionals. While other factors show very low but positive relationship. The findings was also supported by previous studies on work/family \& family/work interference which shows that the strongest positive association of work home interference was with job demands (Joshua, Wukatda, Yohann, 2011)

\subsubsection{Family work interference}

The correlation between the Family work interference and and specific job purpose $(.325, \mathrm{p}=.000)$ self efficacy $(.232, p=.000)$ Motivation $(.195, p=.000)$ Interpersonal communication $(.138, p=.000)$ at $5 \%$. Level is positive but very low. This is supported by previous studies related to family-work interference and balance. Females who experience high levels of home pressure and a lack of autonomy at home who experience negative feelings at home that spill over to their work domain. As a result, females worry about their home at work and may fail to fulfill their work obligations. The individual will lack the energy required to participate at work because her resources were not replenished at home.(Van Aarde \& Mostert 2008) Home Work Intereference mediates the relation- ship between work characteristics such as job performance. HWI level was very low and at the moment However, it is a predictor of burnout and its mediating role is very potent and should not be neglected (Gandi Et Al 2011)

\subsubsection{Motivation}

Motovation is highly and positively correlated to career satisfaction(.627, $\mathrm{p}=.000)$, specific job purpose $(.610, \mathrm{p}=.000)$, employer efforts $(.600, \mathrm{p}=.000)$, Interpersonal communication $(.568, \mathrm{p}=.000)$ and self efficacy $(.526, \mathrm{p}=.000)$ at $5 \%$ level. This finding was supported by previous research which concludes Motivation has strong contributory effects on driving satisfaction towards career. (Adnan, Mubarak 2010)

\subsubsection{Career satisfaction}

Career satisfaction and Interpersonal communication $(.550, \mathrm{p}=.000)$ specific to job purpose $(.546$, $\mathrm{p}=.000)$ efforts by employer $(.537, \mathrm{p}=.000)$, self efficacy $(.536, \mathrm{p}=.000)$ have positive correlation at $5 \%$ level Career satisfaction is largely a matter of an individual comparing his/her career and life expectations with those being offered (Raduan, Loh, Jegak and Khairuddin 2006) In a study conducted on job satisfaction and career satisfaction Adnan, mubarak (2010) found that Supervisors who have a clear vision and facilitate the acceptance of group goals lead towards satisfaction with different parameters associated with career. This builds a strong relationship with success at work. When more positive rewards are given on out-performance, the employees achieve concrete success in terms of career growth, compensation and supervisor's satisfaction. The reverse is also true when performance is low. This implies that career satisfaction is positively correlated to Interpersonal communication, specific job purpose, efforts by employer and self efficacy. There is a negative correlation between career satisfaction $(-.233, \mathrm{p}=.000)$ motivation $(-.145, \mathrm{p}=.000)$ Interpersonal communication $(-.133, \mathrm{p}=.000)$ specific job purpose $(-.133, \mathrm{p}=.000)$ Efforts by employer $(-.129, \mathrm{p}=.000)$ Self efficacy $(-.128$, $\mathrm{p}=.000)$ at $5 \%$ level

\subsubsection{Interpersonal communication}

Interpersonal communication is positively correlated to efforts by employer $(.541, \mathrm{p}=.000)$ specific job purpose $(.503, \mathrm{p}=.000)$ self efficacy $(.462, \mathrm{p}=.000)$ at $5 \%$ level and the this finding is supported by previous research on interpersonal relationship which indicates the interpersonal communication and employer efforts towards the employee. Serious conflicts on interpersonal communication may cause lose-lose situation and barriers to global success. (Xiaoyan \& Lan 2013) Elena (2010) found that the interpersonal communication and interpersonal relationship are positively correlations.

4.1.16Efforts by employer The correlation between Efforts by employer and specific to job purpose is best supported by the study conducted by Ismail, Samina, Syed (2012) influence of employers provided on-job-training on employees wage growth and job performance. The authors concluded that the Training that is the effort taken by the employer does have a positive impact on job. Efforts by employer correlated to specific to job purpose $(.523, \mathrm{p}=.000)$ self efficacy $(.477, \mathrm{p}=.000)$ at $5 \%$ level

4.1.17 Specific to job purpose Is positively correlated to self efficacy $(.696, p=.000)$ at $5 \%$ level. Self-efficacy is the measure of one's own ability to complete tasks and reach goals. self-efficacy are important in enhancing human performance (Fotini, Sofiai,Choustoulakis 2009) It is the foundation and motive power to produce and increase the autonomous working motivation (Shuyuan, Guihao, Guifeng, Yunlian, Li 2011) Findings of this study is supported by Wendy, Sandra, Johan, Jac (2010). (Hiske, Maarten, Gabe, Wendy, Aart 2010) Organization must invest in training to give people the skills and increase employees' self-efficacy, that is, 
confidence in their own ability to carry out a specific task. High self-efficacy leads to high motivation and vice versa, low self-efficacy leads to low motivation. (Davor 2008)

\subsubsection{Self-Efficacy}

Quality of work life (QWL) has increasingly gained recognition, as employees want to feel respected at work for what they do and who they are. Self efficacy refers to an individuals' belief that he or she is capable of performing a task. The higher your self-efficacy, the more confidence you have in your ability to succeed in a task. So, in difficult situations, we find that people with low self efficacy are more likely to lessen their effort or give up altogether while those with high self efficacy will try harder to master the challenge. Self-Efficacy is defined as the reflects the conviction of a person that he/she can execute behaviours relevant to their own work.

Self-efficacy is one's belief in one's ability to succeed influences his or her level of motivation, the amount of effort expended, the degree of stress experienced, and the extent to which one perseveres in the midst of difficulties and uncertainties. In a study conducted by Hiske, Maarten, Gabe, Wendy, Aart (2010) on occupational therapy for depressed employees they found that by increasing exposure to the working environment, and by stimulating communication between employer and employee, the occupational intervention enhance self-efficacy and the acquisition of more adaptive coping strategies Abigail, Asamani (2013) concluded that employees self efficacy and level of education play a key role in how they discharge their duties and responsibilities, and to a large extent affect their quality of work life

\section{Conclusion}

The study has been successful in accomplishing its research objectives. Predominant factors which influence the Quality of work life was identified. 18 factors were derived they are employee relationship, Work nature, Job autonomy, Job security, Work environment, Social environment, Psychological environment, Physical health, Depressive symptom, work stress, Work family interference, family work interference, Motivation, career satisfaction, interpersonal communication, efforts by employer, specified to job purpose and self-efficacy.

The factors emerging from "quality of working life experiences" also indicate that how they are employed differently to satisfy the various needs of the employees by various organizations, which in turn elicit favorable job-related responses. Based upon an understanding of employees' various needs and their QWL experiences, management can identify the strategic gap (if any) in the organization and can take further necessary actions to improve the QWL of employees. This may be helpful for an organization to be successful and to achieve organizational (Chandranshu 2012). The relationship between the Quality of work life and the factors were found. It shows that majority of the factors are positively correlated to the quality of work life.

Employee relationship is positively correlated to all the factors of Quality of work life. The relationship between management, employer, employee and peer does have great impact in the work life of an individual. The relationship between the factors has been discussed with the literature support. The study has explored some new components of Quality of Work life, so researchers and scholars may conduct the studies to confirm these components.

\section{Reference}

[1]. Abigail Opoku Mensah, Asamani Lebbaeus The Influence of Employees' Self-Efficacy on Their Quality of Work Life: The Case of Cape Coast, Ghana, International Journal of Business and Social Science, 4(2), 2013, 195 -204

[2]. Adele Van Aarde, Karina Mostert, Work-home interaction of working females: What is the role of job and home characteristics, SA Journal of Industrial Psychology 34(3) 2008

[3]. Adnan Riaz, Mubarak Hussain Haider, Role of transformational and transactional leadership on job satisfaction and career satisfaction, BEH - Business and Economic Horizons 1(1) 2011 29-38

[4]. Ayesha Tabassum, Interrelations between Quality of work life dimensions and faculty member job satisfaction in private universities of Bangladesh 2012

[5]. Alireza Bolhari, Ali Rezaeean, Jafar Bolhari, Sona Bairamzadeh, and Amir Arzi Soltan, The relationship between QWL and demographic characteristics of Information Technology Staffs, International conference on Computer communication and management 5, 2011

[6]. Chris Obisi, Employee Training and Development in Nigerian Organisaitons: Some Observations and Agenda for Research, Australian Journal of Business and Management Research, 1(9), 2011, 82-91

[7]. Emin Cihan Duyan, Serpil Aytac, Neslihan Akyildiz, Darren van Laar, Mediterranean journal of social science, 4(1) 2013.

[8]. Farideh Haghshenas Kashani,A Review on Relationship between Quality of Work Life and Organizational, Citizenship Behavior, J. Basic. Appl. Res., 2(9), 2012, 9523-9531

[9]. Forgeard, M. J. C., Jayawickreme, E., Kern, M. \& Seligman, M. E. P. Doing the right thing: Measuring wellbeing for public policy. International Journal of Wellbeing, 1(1), 2011, 79-106. doi:10.5502/ijw.v1i1.15

[10]. Fotini Paraskeva, Sofia Mysirlaki, E. Choustoulakis 2009 Designing Collaborative Learning Environments Using Educational Scenarios Based on SR, International journal of Advanced corporate learning 2(1) DOI: http://dx.doi.org/10.3991\%2Fijac.v2i1.606

[11]. Graham S. Lowe, Healthy workplace strategies: Creating change and achieving results prepared for the work place health strategies bureau health Canada, The Graham Lowe Group Inc 2004

[12]. Guna Seelan Rethinam, Maimunah Ismail, Constructs of Quality of Work Life: A Perspective of Information and Technology Professionals, European Journal of Social Sciences - 7(1), 2008 
[13]. Ismail Khan, Samina Nawab, Syed Sikandar Wali 2012, Influence of employer's provided on-the job training on employees wage growth and job performance: An Empeirical evidence of telecommunication industry of Pakistan, SAVAP International, 3(2), 579 588

[14]. Hiske L Hees, Maarten WJ Koeter, Gabe de Vries, Wendy Ooteman, Aart H Schene, Effectiveness of adjuvant occupational therapy in employn ees with depression: design of a randomized controlled trial, BMC Public Health, 10, 2010, 558

[15]. Indhumathy. R \& Kamalraj. S, A Study on QWL among workers with special reference to textile industry in Tirupur District - A Textile hub, International Journal of Multidisciplinary Research, 2(4), 2012

[16]. Sheng Wen Liu, Ralph Norcio, Jung Tsung Tu, The Differences in Job Characteristics, Job Satisfaction, and Organizational Commitment of Taiwanese Expatriates Working in Mainland China, International Journal of Business and Management 4(11), 2009

[17]. Lokanadha Reddy.M, Mohan Reddy, Quality of work life of employees: emerging dimensions, Asian journal of management, 2010, $827-839$

[18]. Meenakshi Gupta, Parul Sharma, Factor credentials boosting quality of work life of BSNL employees in Jammu region, APJRBM, 2(1) 2011, $79-89$

[19]. M.S. Hayrol Azril, U. Jegak, M. Asiah, A. Noor Azman, A.S. Bahaman, Can Quality of Work Life Affect Work Performance among Government Agriculture Extension Officers? A Case from Malaysia, Journal of Social Sciences 6 (1), 2010, 64-73

[20]. M. Swapna \& S. Gomathi, A Study on the Interplay between the Constructs of Quality of Work life: With Special Reference to IT Professionals in Bangalore City, Asian Social Science 9(9), 2013, 107 - 122

[21]. Pallavi P. Kulkarni, A Literature review on training and velopment and Quality of work life, Journal of Arts, Science \& Commerce, 4(2), 2013 136-143

[22]. Pugalendhi, Subburethina Bharathi and M, Umaselvi and Nakkeeran, Senthil, Quality of work life: Perception of College teachers , Indian journal of commerce \& Management studies, 2(1) 2011. 47-65

[23]. Shalini Sheel, DR. Bhawna Khosla Sindhwani, Shashank Goel; Sunil Pathak, Quality of Work life, Employee performance and Career growth opportunities: A Literature review, International Journal of Multidisciplinary Research, 2(2) 2012

[24]. Shuyuan Cheng, Guihao Liu, Guifeng Xu, Yunlian Xue, Li Guo, Primary and Secondary School Counseling Staff Self-Efficacy Relevant Factors, Scientific research, 2(3), 2011 226-229 DOI:10.4236/psych.2011.23035

[25]. Simon Easton \& Darren Van Laar, User Manual for the work-related Quality of life (WRQoL) scale, A Measure of Quality of working life, University of Portsmouth, UK 2012

[26]. Simonetta Manfredi and Michelle Holliday, Work-Life Balance, An audit of staff experience at Oxford Brookes University, The Centre for Diversity Policy Research, Oxford Brookes University, 2004

[27]. Subaashnii Suppramaniam, Fitriya Abdul Rahim, Thilageswary A Rumugam, Quality of Work Life : A Look at the Factors Affecting

[28]. Xiaoyan Zhang \& Lan Huang , Cross-Culture Influences on Interpersonal Relationship in Communication Management A Case Study: Foreign Supervisors PK Chinese Employees in Foreign-Invested Enterprises, International Journal of Business and Management; 8(12); 2013,117 -125

[29]. Yusef Sofi, Somayeh Razzaghi, Jalil Hajelo, A Survey of Relationship between Work Life Quality and Staffs Participation in Payame Noor University, Iran, J.Basic. Appl. Sci. Res., 2(9), 2012, 9314 -9320 